Supplement of Geosci. Model Dev., 8, 3733-3746, 2015

http://www.geosci-model-dev.net/8/3733/2015/

doi:10.5194/gmd-8-3733-2015-supplement

(C) Author(s) 2015. CC Attribution 3.0 License.

(c) (i)

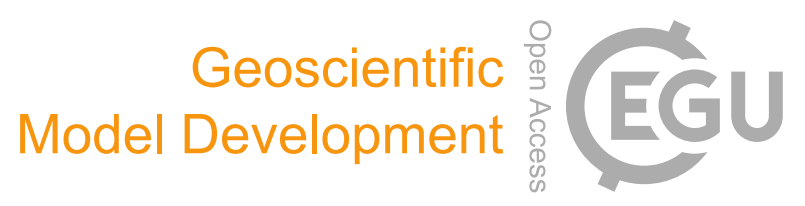

Supplement of

\title{
Updating sea spray aerosol emissions in the Community Multiscale Air Quality (CMAQ) model version 5.0.2
}

\section{B. Gantt et al.}

Correspondence to: J. O. Bash (bash.jesse@epa.gov)

The copyright of individual parts of the supplement might differ from the CC-BY 3.0 licence. 


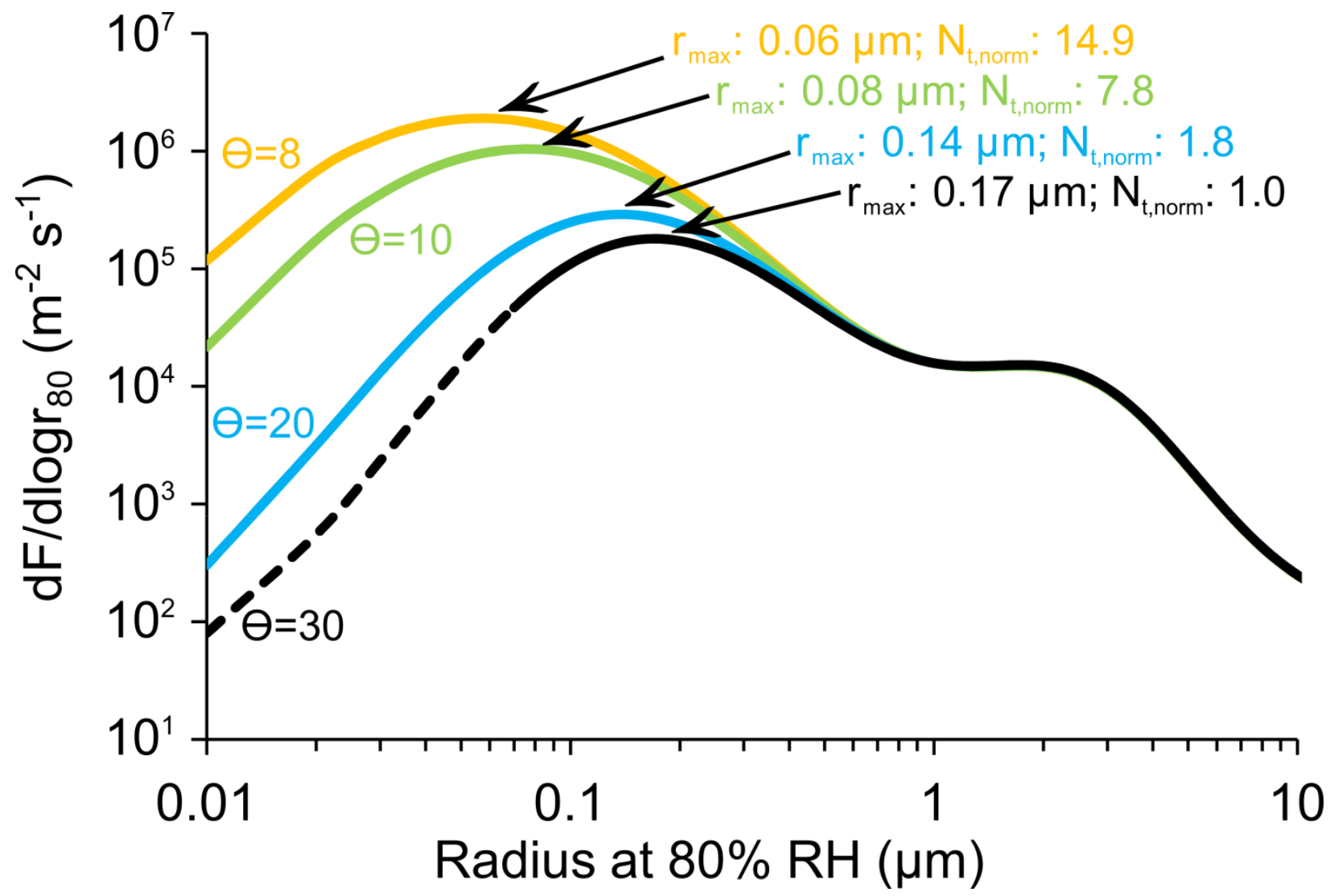

Figure S1. Comparison of the Gong (2003) sea-salt emission size distribution using $\Theta$ values of $30,20,10$, and 8 at a wind speed of $8 \mathrm{~m} \mathrm{~s}^{-1}$. $\mathrm{N}_{\mathrm{t}, \text { norm }}$ is the total SSA number emission rate normalized to Gong (2003) using a $\Theta$ value of 30 . 


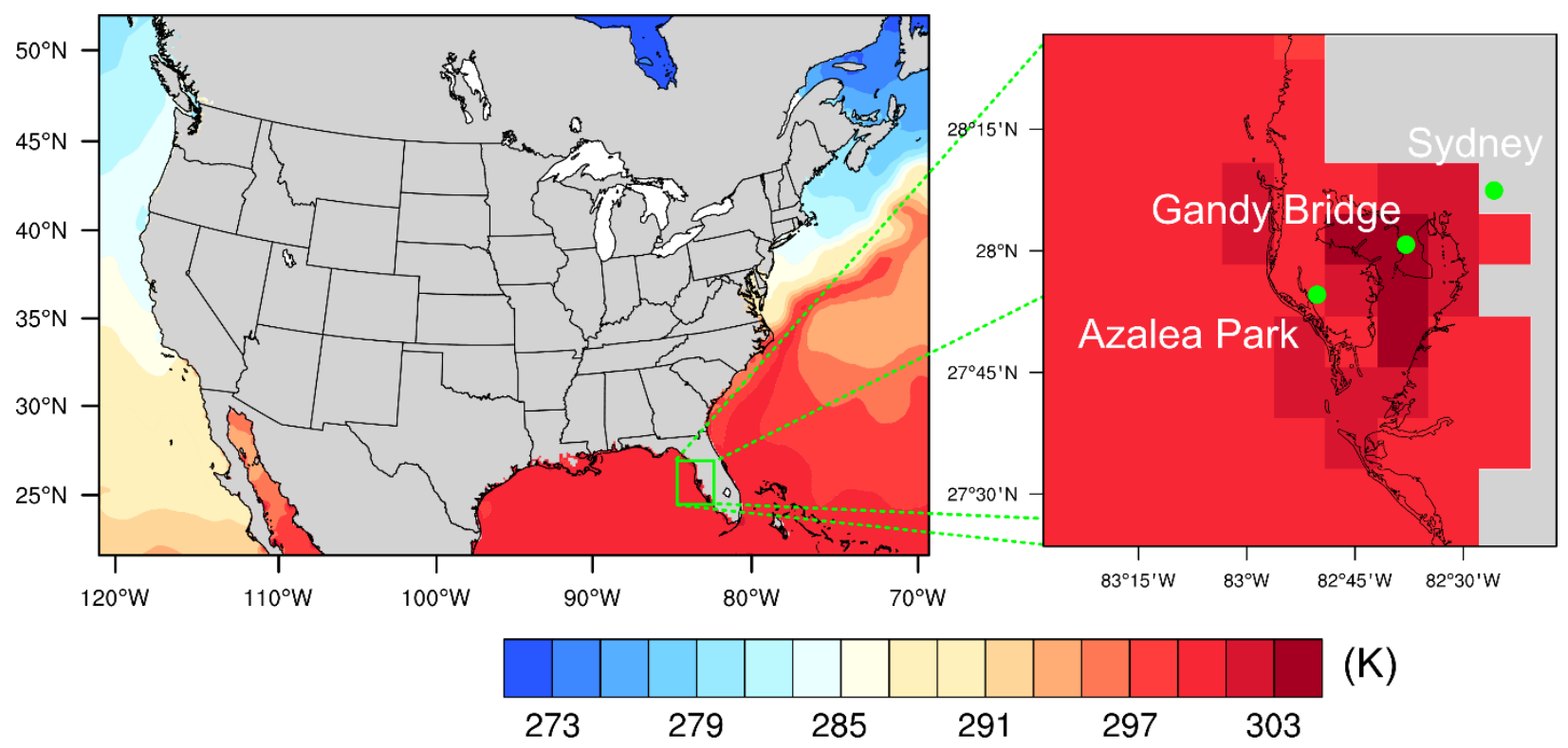

Figure S2. Sea surface temperature (in kelvin) for May 2002 over the continental U.S. and BRACE domains with sites from left to right of Azalea Park, Gandy Bridge, and Sydney as green dots. 

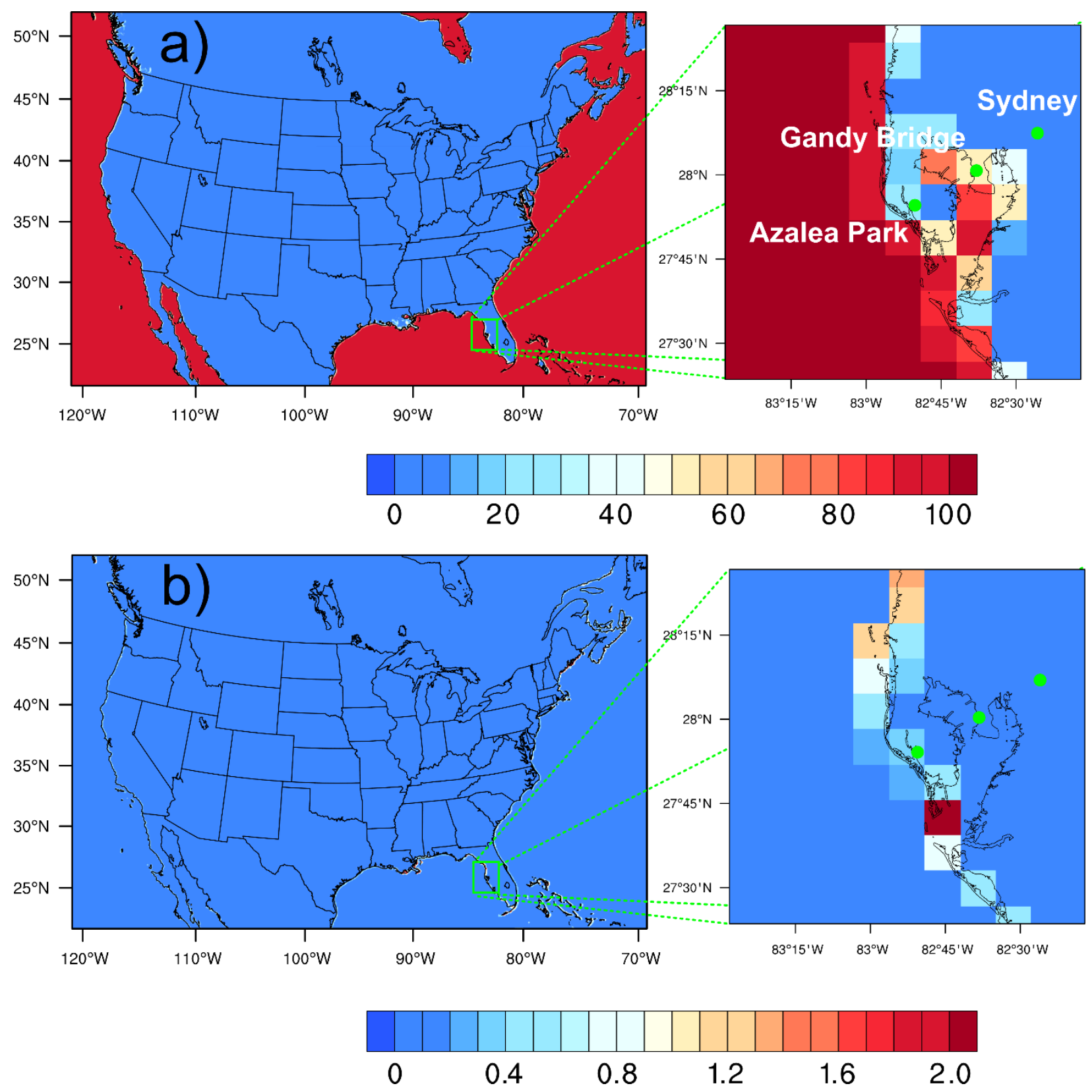

Figure S3. Fraction of each CMAQ grid cell designated as a)open ocean and b)within 50 meter surf zone for the continental U.S. and BRACE domains with sites from left to right of Azalea Park, Gandy Bridge, and Sydney as green dots. 

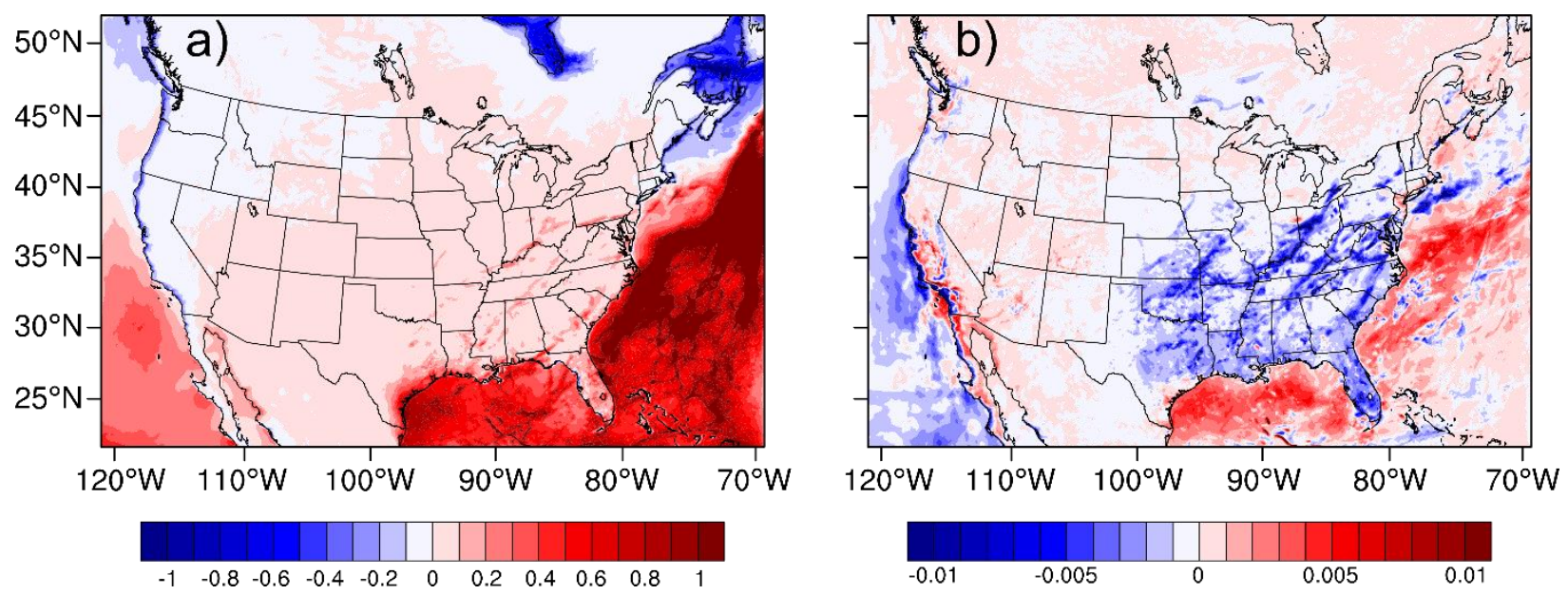

Figure S4. Change in the total (wet+dry for all aerosol modes) deposition of a) sodium (in units of $\mathrm{kg} \mathrm{Na}$ hectare ${ }^{-1}$ ) and b) nitrate (in units of $\mathrm{kg} \mathrm{N}_{\text {hectare }}{ }^{-1}$ ) between the Revised and Baseline simulations for May 2002 over the continental U.S. 